\title{
Risk assessment for universities and hospitals restaurants in Gaza, Palestine, in 2012
}

\author{
Darwiesh MK, $\mathrm{MSc}^{1}$, Al-Hindi AI, $\mathrm{PhD}^{2 *}$ \\ 1- MSc Student, Faculty of Science, Islamic University of Gaza, Gaza, Palestine. 2- Professor, Dept. of Medical Laboratory \\ Sciences, Faculty of Health Sciences, Islamic University of Gaza, Gaza, Palestine.
}

\begin{abstract}
Received: February 2014, Accepted: January 2015

Background: A cross-sectional analytic method was used to assess health and safety risks that really matter in restaurants of universities and hospitals in the Gaza strip, Palestine.

Materials and methods: A 40-item questionnaire was completed by workers in all university and governmental hospital restaurants in the Gaza strip. Another 30-item questionnaire was completed by university students, in addition to 40 checklists and 40 personal meetings were conducted by the researcher. The collected data were analyzed by the risk score matrix to detect the risk level (low, medium, high, and very high) for each risk factor.

Results: In general, university and hospital restaurants were similar in terms of risk, but the details differed. The results showed that $22.7 \%$ of physical and electrical risk factors in universities were at a very high risk level. It was found that $50.0 \%$ of cleanliness of the location and equipment risk factors were at a high risk level, and $60.0 \%$ of machinery and equipment risk factors were at a moderate risk level. In addition, the most frequently observed risk factor was employees' and customers' safety and health. The results on hospital restaurants showed $75 \%$ of physical and electrical risk factor and machinery and equipment risk factor were at a moderate level and high level, respectively.

Conclusions: It can be concluded that hospital and university restaurants are similar in terms of risks and levels of risks. Moreover, restaurant employees, cleaners, organization employees, visitors, university students, and patients in hospitals may be at risk if exposure to hazards. Therefore, the development and implementation of a plan with specific measures to address the identified risks is recommended.
\end{abstract}

Keywords: Risk, Assessment, Restaurants, Universities, Hospitals.

\section{Introduction}

Risk is defined as the uncertainty of outcome, whether positive opportunity or negative threat, of actions and events. Risk has to be assessed in respect of the combination of the likelihood of something happening and the impact of its occurrence. Risk management includes identifying and assessing risks (the "inherent risks"), and then, responding to them (1). The restaurant industry could have significant risks, so it must be carefully analyzed to ensure that hazards associated with this occupation are identified and the risks of those hazards are assessed. Once the level of risk is known, control measures can be put in place to reduce it. The lower the level of risk an occupation presents, the less chance of an accident occurring in that occupation (2).
According to the author's knowledge, there is no available data on the different risk factors in university and hospital restaurants in Gaza, Palestine. The majority of studies carried out in Gaza were related to health risks or food contaminations. Recently, in Gaza, interest toward restaurants and the quality of food provided has been growing; however, still little attention is paid to the numerous risks in restaurants. The central Public Health Laboratory (PHL) in Palestine in 2005 collected a total of 9,435 food samples (3.022 in the Gaza strip and 6,413 in the West Bank) for bacteriological examinations (3).

\footnotetext{
* Corresponding author: Adnan Al-Hindi, Dept. of Medical laboratory Sciences, Faculty of Health Sciences, Islamic University of Gaza, Gaza, Palestine. Email: ahindi@iugaza.edu.ps
} 
According to their reports, $20.5 \%$ of the food samples collected was contaminated $(16.7 \%$ in the West Bank and 28.5\% in the Gaza strip). Among the food contaminations found in microbiological examination, coliform and yeast had the highest rates (3). The present study will address the following aims: (a) to assess risks that are of importance in restaurants of universities and hospitals in the Gaza strip; (b) to consider health and safety risks with the potential to cause harm for workers, guests, and properties at these restaurants; (c) to detect the level of risks (low, medium, high, and very high) using the risk score matrix; (d) to determine which types of restaurants (universities, hospitals) are more at risk; and (e) to detect the most frequent risk factors in restaurants. This study was performed in order to recommend interventions to treat potential work place risks of the study areas.

\section{Materials and Methods}

This was a cross-sectional analytical study carried out on all university and hospital restaurants in the Gaza strip from November 2011 to May 2012.

An approval was obtained from the Ministry of Health and all Universities participated in the study in $7 / 5 / 2012$. Informed consents were obtained from every participant.

The target population of this study consisted of restaurants in two sectors:

1- The high education sector represented by universities.

2- The health sector represented by governmental hospitals.

According to the Ministry of education and high education, 7 universities have a valid license: Islamic University of Gaza (IUG), AlAzhar, Al-Aqsa, University of Gaza, ALOmma, Palestine, and AL-Quds Open University. The largest university was IUG in terms of the number of students; as the number of students in the year 2011 reached 20.000 (8.000 male, 12.000 female). The number of governmental hospitals was 13 , but not all hospital had restaurants; Al-Shifa Hospital does not have a restaurant due to the new daily delivery system of ready meals by a contracted company.

The restaurant of the Rantisi Pediatric Hospital in the Gaza strip provides daily meals for 5 hospitals: Al-Naser, Eyes, Psychiatry, and Durra, in addition to Rantisi Pediatric Hospital itself.

The restaurant of Kamal Adwan Hospital in Northern Gaza offers its services to its hospital as well as the Beit-Hanoun Hospital. All the remaining hospitals have restaurant inside their buildings; Al-Aqsa Hospital in the middle zone of the Gaza strip, the Nasser Hospital and European Hospital in Khan Younis in Southern Gaza, Abu Yousef Al Najjar Hospital in Rafah in Southern Gaza, and United Arab Emirates Crescent Hospital in Rafah in Southern Gaza. The study population consisted of 70 samples divided into 2 categories. The first category included 40 workers, in addition to kitchen managers. The second category contained 30 students (males and females), and university staff.

All headquarters of universities, and governmental hospitals in the Gaza strip, Palestine, were studied. All students registered in each university, and restaurant workers and managers were enrolled into the study.

\section{Procedures}

Data collection was performed using 4 tools:

1. A structured self-report questionnaire: In each restaurant, 2-3 workers were asked to completed a questionnaire including data and questions about the types of risks in restaurants and 3-4 students completed another questionnaire.

\section{Construction of questionnaire no. 1}

A structured face-to-face questionnaire with closed-ended questions was conducted by the researcher. To construct the questionnaire, the researcher used different guidelines and references which were concerned with restaurant risk assessment, such as workplace health and safety hazard identification 
constructed by Workplace Health and Safety Queensland (4), restaurant and cafe risk management guide issued by the Wesfarmers General Insurance Limited, and example risk assessment for food preparation, cooking, and service issued by the Health and Safety Executive (5).

The questionnaire included questions related to the 8 risk factors of slips, trips and falls, workers, customer safety and health, physical and electrical risks, machinery and equipment, food deliveries, food contamination, cleanliness of location and equipment, employee training, the type of restaurant, and the number of workers.

\section{Construction of questionnaire no. 2}

A structured face-to-face questionnaire with close-ended questions was conducted by the researcher to collect data about university cafeterias. The questionnaire included questions related to slips and falls, and physical conditions of the cafeteria. In the present study, the risk score matrix was adopted for the two questionnaires to investigate severity and likelihood in the questionnaire, and then, to determine the level of each detected risk.
Checklist: In every restaurant, the researcher walked around the kitchen, the stockroom, and all other areas noting things that might pose a risk, and filling a check-list used to verify the availability of specific conditions, like ventilation and lighting in the kitchen, working of the refrigerator temperatures organizer, and safety conditions for workers.

Personal meeting: In each group of staff, some workers were interviewed using specific questions with multiple choice answers, like "Who is responsible for the controlling of insects and rodents in the restaurant?"; and "What are the most common problems you are facing at work?". The last two questions were open ended. Using this tool, the researcher listened to workers' concerns and opinions about health and safety conditions at the work place.

\section{Processing of collected data}

The collected data have been processed by two methods:

The risk score matrix was used to analyze the threat of greatest concern, and detect the risk level (6) (Figures 1).

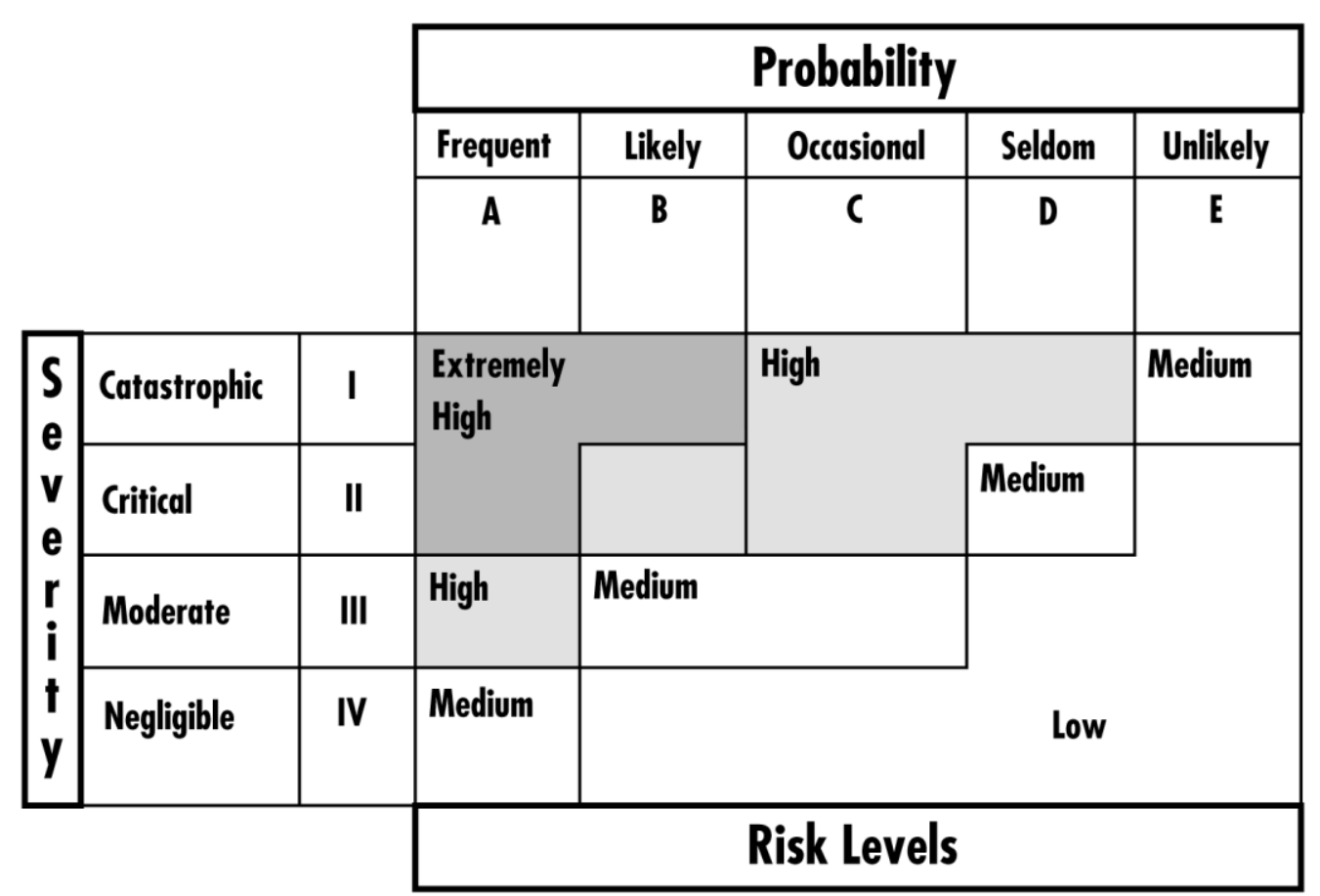

Figure 1: Threat evaluation matrix (7) 
Data analysis was performed using the Statistical Package for the Social Sciences (version 15; SPSS Inc., Chicago, IL, USA) to compare the variables. Z-test was used to examine the statistical difference between two population proportions. Chi-square test was used to examine the statistical difference between more than two population proportions and the relationship between two nominal (qualitative) variables. If $\mathrm{P}$-value is smaller than the level of significance and $\alpha$ is equal to 0.05 , then there exists a significant relationship between the given proportions.

\section{Results}

\section{Comparisons for each factor between} restaurants (hospitals and universities)

\section{Slips and falls}

The low risk level (LRL) for slips and falls was higher in hospital restaurants than university restaurants; the proportions for hospitals and universities equaled $86.1 \%$ and $77.3 \%$, respectively. The moderate risk level (MRL) of university restaurants was higher than hospital restaurants; the proportions for hospitals and universities equaled $8.3 \%$ and $13.6 \%$, respectively. The high risk level (HRL) of university restaurants was higher than hospital restaurants; the proportions for hospitals and universities equaled 5.6\% and $9.1 \%$, respectively. The LRL of workers' and customers' safety and health, physical and electrical risks, and machinery and equipment risks, was higher in university restaurants than hospital restaurants. The LRL of food deliveries was similar for both university and hospital restaurants. The proportions of LRL for food contamination of hospitals and universities equaled $77.8 \%$. The LRL of cleanliness of location and equipment varied between hospital and university restaurants. Employee training LRL seems to be similar in both groups (Figures 2 and 3).

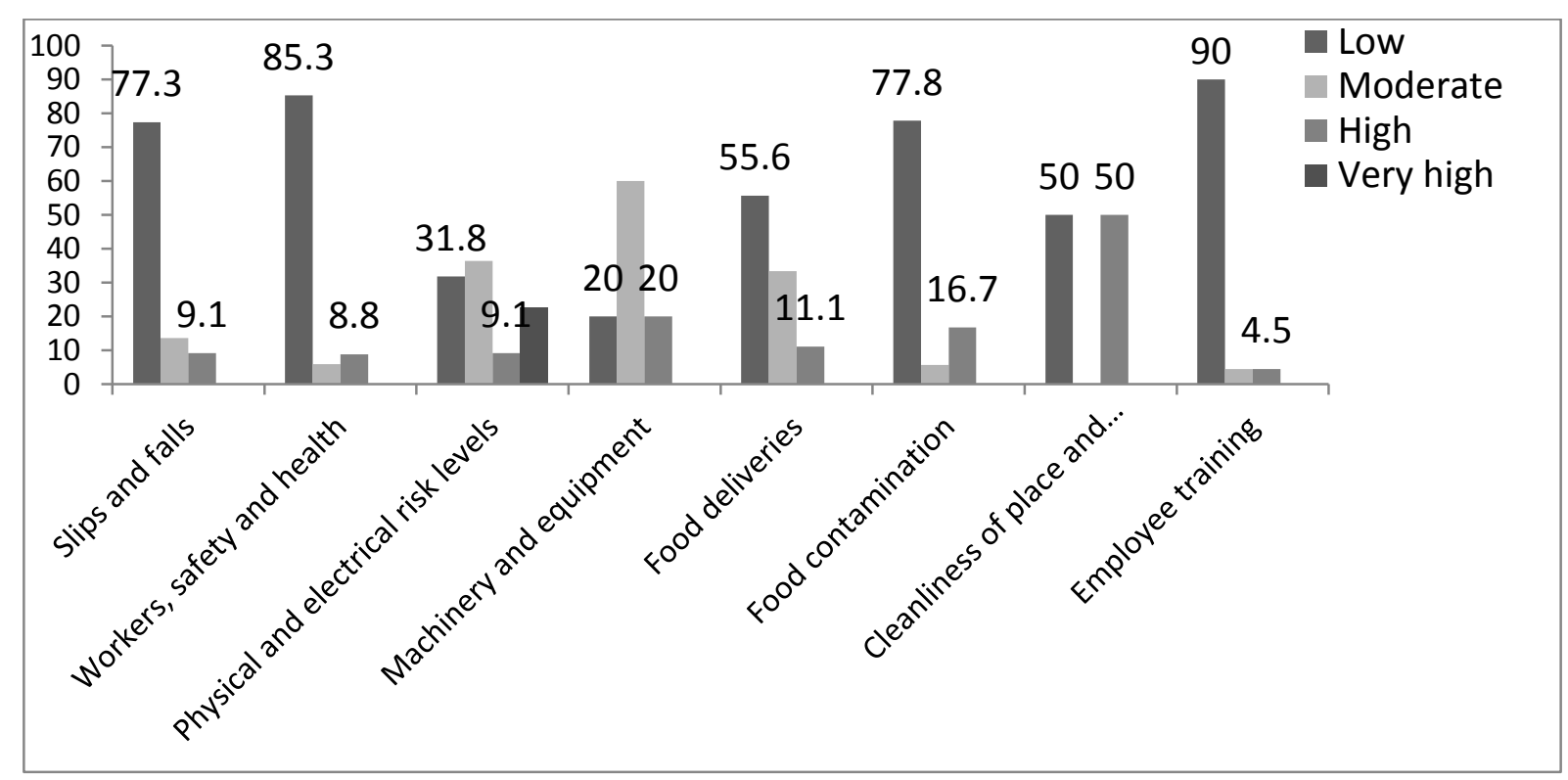

Figure 2: Comparison of all factors between university restaurants 


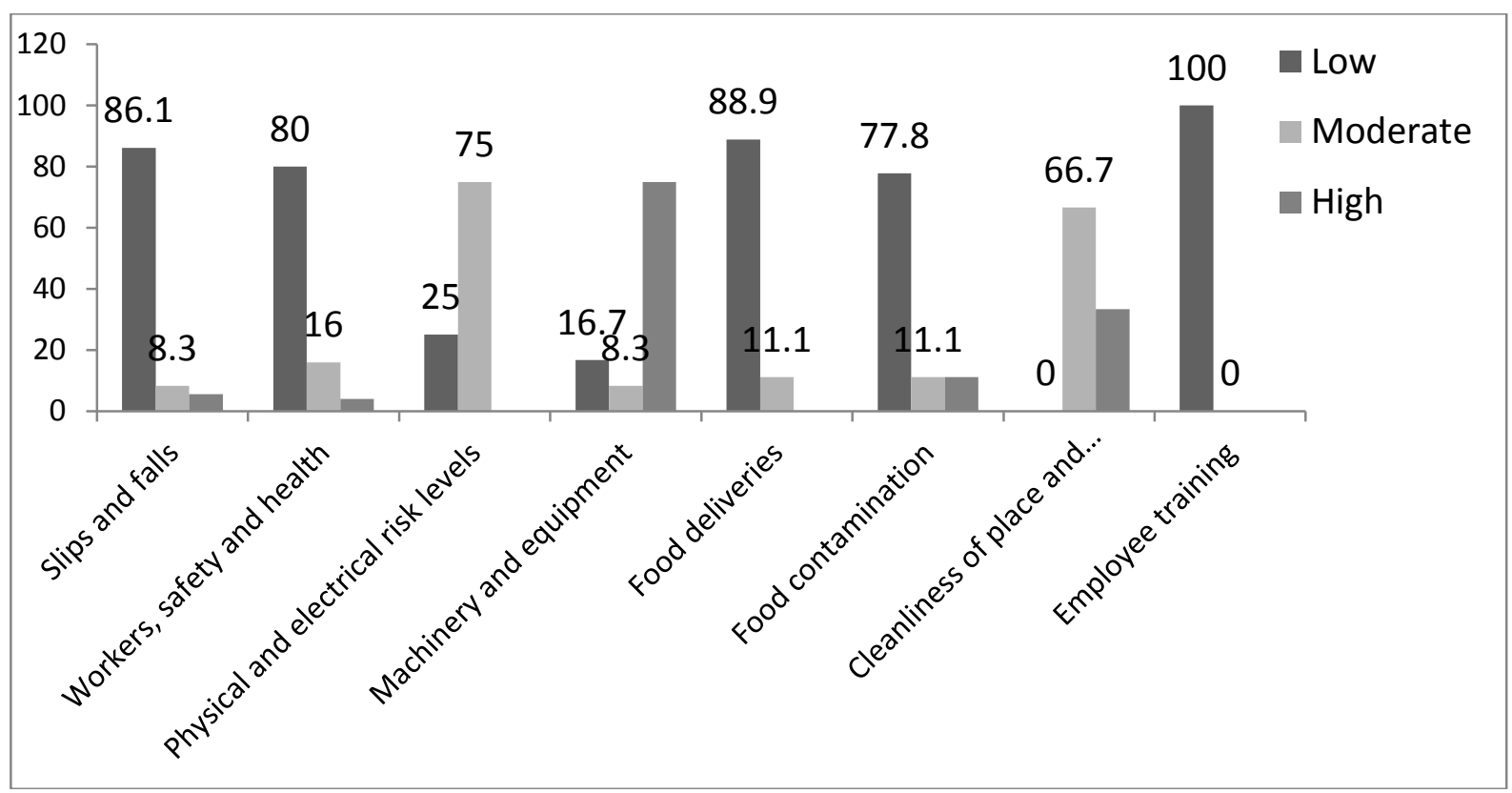

Figure 3: Comparison of all factors between hospital restaurants

\section{Comparison of all risk factors and their levels in general}

The LRL (94.1\%) of the employee training factor is significantly higher than other factors $(\mathrm{P}=0.001)$. The MRL $(42.3 \%)$ of the physical and electrical risks factor is significantly higher than other factors $(\mathrm{P}=0.001)$. The HRL $(58.8 \%)$ of the machinery and equipment factor is significantly higher than other factors $(\mathrm{P}=0.001)$. Only the physical and electrical risks factor has a very high risk level (VHRL) (19.2\%) (Table 1).

Table 1: Comparisons of risk factors

\begin{tabular}{|c|c|c|c|c|c|c|c|c|c|c|}
\hline Risk level & $\begin{array}{c}\text { Slips and } \\
\text { falls } \\
(\%)\end{array}$ & $\begin{array}{c}\text { Workers' and } \\
\text { customers' } \\
\text { safety and } \\
\text { health } \\
(\%)\end{array}$ & $\begin{array}{l}\text { Physical } \\
\text { and } \\
\text { electrical } \\
\text { risks } \\
(\%)\end{array}$ & $\begin{array}{c}\text { Machinery } \\
\text { and } \\
\text { equipment } \\
(\%)\end{array}$ & $\begin{array}{c}\text { Food } \\
\text { deliveri } \\
\text { es } \\
(\%)\end{array}$ & $\begin{array}{c}\text { Food } \\
\text { contamina } \\
\text { tion } \\
(\%)\end{array}$ & $\begin{array}{c}\text { Cleanliness of } \\
\text { location and } \\
\text { equipment } \\
(\%)\end{array}$ & $\begin{array}{c}\text { Employee } \\
\text { training } \\
(\%)\end{array}$ & $\chi^{2}$ & P-value \\
\hline Low & 82.8 & 83.1 & 30.8 & 17.6 & 77.8 & 77.8 & 20.0 & 94.1 & 216.9 & $0.001 *$ \\
\hline Moderate & 10.3 & 10.2 & 42.3 & 23.5 & 18.5 & 7.4 & 40.0 & 2.9 & 80.3 & $0.001 *$ \\
\hline High & 6.9 & 6.8 & 7.7 & 58.8 & 3.7 & 14.8 & 40.0 & 2.9 & 164.3 & $0.001 *$ \\
\hline Very High & - & - & 19.2 & - & - & - & - & - & NA & \\
\hline
\end{tabular}

* The proportion difference is significant at the 0.05 level.

NA: There are not enough valid cases for the chi-square test

\section{Results of workers' interviews}

Table 2 presents restaurant workers' ages; the highest age at hospital and university restaurants were 55 years and 35 years, respectively. Half of university workers perform regular medical examination for infectious diseases, while $95 \%$ of workers at hospitals perform regular examination. Similar results were obtained on using oil for frying two times in university and hospital restaurants. In universities restaurants, oil used for frying was used more than three times. 
Table 2: Results of workers' interviews in the restaurants

\begin{tabular}{|c|c|c|c|}
\hline & $\begin{array}{l}\text { Total } \\
\mathrm{N}(\%) \\
\end{array}$ & $\begin{array}{l}\text { Hospitals } \\
\mathrm{N}(\%)\end{array}$ & $\begin{array}{c}\text { Universities } \\
\mathrm{N}(\%)\end{array}$ \\
\hline \multicolumn{4}{|l|}{ Ages of workers in the restaurant } \\
\hline $18-25$ & $5(12.5)$ & $0(0)$ & $5(25.0)$ \\
\hline $26-35$ & $7(17.5)$ & $0(0)$ & $7(35.0)$ \\
\hline $36-45$ & $7(17.5)$ & $5(25.0)$ & $2(10.0)$ \\
\hline $46-55$ & $21(52.5)$ & $15(75.0)$ & $6(30.0)$ \\
\hline \multicolumn{4}{|l|}{ Regular medical examination } \\
\hline Yes & $29(72.5)$ & $19(95.0)$ & $10(50.0)$ \\
\hline No & $11(27.5)$ & $1(5.0)$ & $10(50.0)$ \\
\hline \multicolumn{4}{|l|}{$\begin{array}{l}\text { Number of times of using the same oil } \\
\text { for frying }\end{array}$} \\
\hline 1.00 & $16(50.0)$ & $15(75.0)$ & $1(8.3)$ \\
\hline 2.00 & $8(25.0)$ & $5(25.0)$ & $3(25.0)$ \\
\hline 3.00 & $3(9.4)$ & $0(0)$ & $3(25.0)$ \\
\hline 6.00 & $3(9.4)$ & $0(0)$ & $3(25.0)$ \\
\hline 7.00 & $1(3.1)$ & $0(0)$ & $1(8.3)$ \\
\hline 10.00 & $1(3.1)$ & $0(0)$ & $1(8.3)$ \\
\hline \multicolumn{4}{|l|}{$\begin{array}{l}\text { Who is responsible for controlling } \\
\text { insects and rodents? }\end{array}$} \\
\hline Restaurant workers & $18(46.2)$ & $0(0)$ & $18(90.0)$ \\
\hline Department of health in the organization & $4(10.3)$ & $3(15.0)$ & $1(5.0)$ \\
\hline Specialized companies & $17(43.6)$ & $17(85.0)$ & $1(5.0)$ \\
\hline
\end{tabular}

Workers reported the common problems they faced in their work place as shown in table 3 . The first problem is lack of staff.

\section{Results of the checklist for workers}

All hospital workers wore uniforms during work hours, while only $25.0 \%$ of university workers wore uniforms. The rate of bathroom cleanness was $75.0 \%$ and $42.86 \%$ for hospital and university restaurants, respectively. Nearly $43 \%$ of hospital kitchens and $87.5 \%$ of university kitchens had sufficient ventilation. All laundries and sinks in university restaurants were in good conditions, while $42.9 \%$ of laundries and sinks in hospital restaurants had a water leakage or rash (Table4.)

Table 3: The most common problems presented in restaurants as reported by the workers

\begin{tabular}{lcc}
\hline \multicolumn{1}{c}{ Problems } & Hospitals (\%) & Universities (\%) \\
\hline Lack of staff & 85 & 30 \\
Inadequate equipment & 50 & 30 \\
Delayed maintenance of damaged equipment & 60 & 5 \\
Limited space & 30 & 25 \\
Need for training courses & 40 & 15 \\
\hline
\end{tabular}


Table 4: Results of the checklist for workers

\begin{tabular}{|c|c|c|c|c|}
\hline Variable & Answers & $\begin{array}{l}\text { Total } \\
\text { N }(\%)\end{array}$ & $\begin{array}{c}\text { Hospitals } \\
\mathrm{N}(\%)\end{array}$ & $\begin{array}{c}\text { Universities } \\
\mathrm{N}(\%)\end{array}$ \\
\hline \multirow{2}{*}{ Number of workers wearing uniform } & Yes & $9(60.0)$ & $7(100.0)$ & $2(25.0)$ \\
\hline & No & $6(40.0)$ & & $6(75.0)$ \\
\hline \multirow{2}{*}{ Working of temperatures organizer of the refrigerator } & Yes & $12(80.0)$ & $6(85.71)$ & $6(75.0)$ \\
\hline & No & $3(20)$ & $1(14.29)$ & $2(25.0)$ \\
\hline \multirow{2}{*}{ Cleanness of workers' bathrooms } & Yes & $9(60.0)$ & $6(75.0)$ & $3(42.86)$ \\
\hline & No & $6(40.0)$ & $2(25.0)$ & $4(57.14)$ \\
\hline \multirow{2}{*}{ Ventilation of the kitchen } & Yes & $10(66.7)$ & $3(42.9)$ & $7(87.5)$ \\
\hline & No & $5(33.3)$ & $4(27.1)$ & $1(12.5)$ \\
\hline \multirow{2}{*}{ lighting of the kitchen } & Yes & $14(93.3)$ & $7(100.0)$ & $7(87.5)$ \\
\hline & No & $1(6.7)$ & & $1(12.5)$ \\
\hline \multirow{2}{*}{ Presence of water leakage in sinks or laundries } & Yes & $3(20.0)$ & $3(42.9)$ & \\
\hline & No & $12(80.0)$ & $4(57.1)$ & $8(100.0)$ \\
\hline
\end{tabular}

Results of the questionnaire for students

The different risks mentioned by the university students are summarized in table 5 .

The difference in the risk levels of the material of floors factor is statistically insignificant.

However, the difference in the risk levels of the factors of absence of wet floor signs and narrow paths between the tables were statistically significant $(\mathrm{P}=0.001)$. The HRL $(68.8 \%)$ was significantly higher than other risk levels (Table 5).

Table 5: Levels of different risks according to university students

\begin{tabular}{|c|c|c|c|c|}
\hline Variable & Risk level & No. $(\%)$ & $\chi^{2}$ & P-value \\
\hline \multirow{4}{*}{ Material of floors } & Low & $1(16.7)$ & \multirow{4}{*}{0.667} & \multirow{4}{*}{0.881} \\
\hline & Moderate & $1(16.7)$ & & \\
\hline & High & $2(33.3)$ & & \\
\hline & Very high & $2(33.3)$ & & \\
\hline \multirow{4}{*}{ Absence of wet floor signs } & Low & $3(12.0)$ & \multirow{4}{*}{17.080} & \multirow{4}{*}{$0.001 *$} \\
\hline & Moderate & $2(8.0)$ & & \\
\hline & High & $15(60.0)$ & & \\
\hline & Very high & $5(20.0)$ & & \\
\hline \multirow{3}{*}{ Shortage of workers in the restaurant } & Moderate & $2(18.2)$ & \multirow{3}{*}{1.273} & \multirow{3}{*}{0.529} \\
\hline & High & $4(36.4)$ & & \\
\hline & Very high & $5(45.5)$ & & \\
\hline \multirow{3}{*}{ Bad state of the tables and chairs } & Low & $3(27.3)$ & \multirow{3}{*}{2.364} & \multirow{3}{*}{0.307} \\
\hline & Moderate & $2(18.2)$ & & \\
\hline & High & $6(54.5)$ & & \\
\hline \multirow{4}{*}{ Narrow paths between the tables } & Low & $2(12.5)$ & \multirow{4}{*}{16.500} & \multirow{4}{*}{$0.001 *$} \\
\hline & Moderate & $1(6.3)$ & & \\
\hline & High & $11(68.8)$ & & \\
\hline & Very high & $2(12.5)$ & & \\
\hline \multirow{3}{*}{ Size of the restaurant } & Moderate & $2(13.3)$ & \multirow{3}{*}{2.800} & \multirow{3}{*}{0.247} \\
\hline & High & $6(40.0)$ & & \\
\hline & Very high & $7(46.7)$ & & \\
\hline \multirow{3}{*}{ Ventilation of the restaurant } & Moderate & $1(10.0)$ & \multirow{3}{*}{2.600} & \multirow{3}{*}{0.273} \\
\hline & High & $4(40.0)$ & & \\
\hline & Very high & $5(50.0)$ & & \\
\hline \multirow{2}{*}{$\begin{array}{l}\text { Discomfort of the students in the location of } \\
\text { receiving meals }\end{array}$} & High & $2(33.3)$ & \multirow{2}{*}{0.667} & \multirow{2}{*}{0.414} \\
\hline & Very high & $4(66.7)$ & & \\
\hline \multirow{3}{*}{ Self-service bars } & Low & $1(14.3)$ & \multirow{3}{*}{2.000} & \multirow{3}{*}{0.368} \\
\hline & High & $4(57.1)$ & & \\
\hline & Very high & $2(28.6)$ & & \\
\hline
\end{tabular}

* P-Value 


\section{Discussion}

The present research is the first to identify, collect, and compare risk factors, and their description, likelihood, and risk levels in restaurants of two important sectors in Gaza strip (universities and hospitals).

\section{Comparison of risk factors between university and hospital restaurants}

University and hospital restaurants were similar in terms of the slips and trips risk factor and its levels. The highest proportion of risk level for this factor was LRL. Despite the agreement between universities and hospitals in terms of the slips and trips factor, there was variation in its level between the two. For example, in the health and safety executive report, it was declared that slips and trips are responsible for $33 \%$ of all major injuries of employees, in $90 \%$ of cases the floor was wet, and $95 \%$ of major slips resulted in broken bones (8). In this study, hospital restaurant workers mentioned slips and trips as the most frequent risk factor at their work place, university restaurant workers mentioned it as the second most frequent risk factor. This is due to the fact that none of the restaurants in the study put up warning signs for wet floor where required. In restaurants of Gaza, this risk is lower because of precautions taken to prevent dangerous injuries such as closing the restaurant doors when cleaning the floor with water, immediate removal of damaged chairs or tables. Moreover, during the present study, entrances, stairs, and ramps of the restaurants were in good conditions and safe. Most university restaurant workers noted the workers' safety and health factor as the most frequent risk factor, whereas most hospital restaurant workers considered it to be the second most frequent. A number of important points were seen as related to this risk factor, like acute shortage in rest places for workers in most study restaurants. Many workers refused to wear gloves, especially in university restaurants, due to it not being comfortable during work. Although the rate of injuries resulting from this risk factor is low, it can be serious in other cases; sprains and strains of muscles and lenders are common among food service workers and improper fitting and repetitive motions are often associated with sprains, strains, and tear injuries in restaurants (9). Electrical equipments are widely used in the restaurant industry. Frequent use and cleaning may cause equipment to become electrically unsafe, electricity can kill and even non-fatal shocks can lead to severe and permanent injuries (10). This is compatible with the present study results, where the physical and electrical risk factor is the only one recorded as very high level in university restaurants. Even in hospital restaurants, this factor came first in the MRL. This is due to the lack of regular testing of electrical systems by a competent electrician. The help of competent electricians is only requested when there is a problem which restaurant workers cannot fix. Moreover, an insufficient number of, and low quality fire extinguishers were observed in restaurants. In general, the highest HRL was that of the machinery and equipment risk factor, and caused by incorrect reassembly of machines and poor maintenance and lack of use of guards. A significant number of accidents are due to inadequate isolation of machines (11). The machinery and equipment risk factor had the highest rate in hospitals with a significant difference to the rate of universities. This is because of the use of different large machines in hospitals to prepare complete meals (breakfast, lunch, and dinner) daily for patients and hospital employees, while university restaurants mainly prepare and serve sandwiches and fast food, which do not need large machines.

The food deliveries factor is considered as one of the ten most important contributory factors in the outbreak of food-borne diseases (12). Although the steps followed in food delivery in the studied restaurants were satisfactory, the shortage of workers in hospitals significantly affected this factor. The delivery of ready meals to patients is a new trial in hospitals of Gaza. In the past meals were prepared in 
hospital kitchens and offered to the patients. University and hospital restaurants are similar in terms of the food contamination risk factor. The level of risk is mainly the result of the lack of reviewing manager information about food contamination by workers and no clear labeling for containers in the kitchens. All hospital restaurant workers were using the same oil once or twice for frying and they followed the instructions of the Ministry of Health since the meals are provided to patients. Much attention is paid to the quality of food to be healthy. While repeated use of oil for frying in private companies in university restaurants has increased due to their prioritization of economic aspects and the absence of monitoring procedures.

The results showed that few workers considered the cleanliness of location and equipment factor as hazardous. This is not compatible with the researcher's direct observation of a low level of cleanliness especially in university restaurants. This is supported by another study which considered this factor as the most commonly cited violation in restaurants (13). In hospitals, the low rate of cleanliness is not limited to restaurants; another study showed the presence of cockroaches in the cabinets of patients in hospitals in Gaza (14).

Employee training risk factor had the lowest rate compared to others. This is due to the requirement of knowledge or previous experience for employees particularly in hospital restaurants and worker training before beginning tasks in both university and hospital restaurants. These results are more satisfactory than those of commercial sectors in Gaza; for example, $58.9 \%$ and $42.2 \%$ of employees of cake bakeries had previous experience and training, respectively (15).

\section{Risks in university restaurants as reported by students}

University restaurants are students' favorite places to rest and eat during the day. The most risk detected was that of the factor of absence of wet floor signs when required; $75 \%$ of students reported it as the first risk, with a statistically significant difference between its levels. This result is logical since the cleaning process is performed more than once a day and students are not alerted by a sign every time which makes them vulnerable to slipping and falling with various expected injuries. This is in agreement with the findings of another study which confirms that most injuries caused by slips and falls in restaurants occur due to slipping on wet floors, and this problem arises during the busies time period of the restaurant when the pace of work increases (9). The narrow corridors between tables factor was detected as the highest VHRL, with a statistical difference between its levels, which is due to the small size of the restaurants. The small size of university restaurants is not limited to Gaza; it is a general phenomenon. For example, about 5000 students eat their meals in Dortmund university restaurant in Germany, while the capacity of the restaurant is only 1500 individuals (16). The highest VHRL was attributed to location and discomfort of students when waiting to receive their meal. Moreover, this was the only risk factor which was divided into only 2 risk levels; HRL and VHRL. This was due to overcrowding of customers when buying meals and waiting for a long time to receive meals the daily repetition of this situation.

\section{Health and safety status of workers}

The present study showed that $60 \%$ and $72.5 \%$ of workers wore uniforms and performed medical examinations for infectious diseases, respectively. These results are similar to that found in a previous study in Gaza governorate (74.7\%, 77.8\%) (8). Hospital employees show greater commitment to implementing health and safety codes than university employees, because of the guidelines of the Ministry of Health for its employees. The highest ages of hospital restaurant employees are higher than their counterparts in universities. Hospital employees are affiliated to the Ministry of Health. The ages of university employees vary, but $60 \%$ of their ages range between 18 and 35 , because businesses tend to employ youths as they are capable of achieving their 
responsibilities and endure occupational pressures.

\section{Restaurant facilities and general health conditions}

Cleanliness of employee bathrooms in hospital restaurants was more satisfactory than university restaurants, since the cleaning in hospitals is carried out by specialized private companies. On the other hand, the employees of private companies that won tenders of universities restaurants are responsible for cleaning employee bathrooms, here the financial factor take part by lowest number of workers for largest number of tasks. However, in both cases, the situation is much more satisfactory than other third world countries like Bangladesh (17). The ventilation of university restaurants is more satisfactory than hospital restaurants because of most of hospital restaurant are found in bedrooms, contrary to most of university restaurant that found above the ground. Despite the differences in those responsible for controlling of insects and rodents in restaurants of universities and hospitals, the two complained of inefficient methods of control, and thus, the presence of health risks. In university restaurants, no water leakage was found in the kitchen sinks, while it was observed in the kitchen sinks of half of the hospital restaurants. This finding was confirmed by the results of problems reported by employees.

In our study, the results indicated that restaurant employees lack knowledge. This finding was in agreement with the results reported by a study in Nigeria (18).

\section{Conclusions}

It can be concluded that hospital and university restaurants are similar in terms of risks and levels of risks. However, they differed in the VHRL of physical and electrical risks factor which was higher in university restaurants than hospital restaurants. A difference was observed in the division of these risks and levels of different risk factors as was previously stated. Individuals or groups of people who may be at risk of exposure to hazards in university and hospital restaurants are restaurant employees, cleaners, organization employees, visitors, university students, and patients in hospitals.

\section{Acknowledgment}

The authors would like to thank all the personnel who participated in this study.

Conflict of interest: Non declared

\section{References}

1. Treasury HM. The Orange Book: Management of Risk - Principles and Concepts. Norwich: Crown; 2004.

2. Work Cover Corporation. Guidelines for reducing the risk of violence at work. $1^{\text {st }}$ Edition. Government of South Australia: Australia; 2002.

3. Palestinian health information center $\mathrm{MOH}$. Health status in Palestine 2005. Palestine 2006; P30-2.

4. Work place health and safety. Café and restaurant industry. Electrical Safety: Queensland, Australia 2010.

5. Health and Safety Executive (HSE). Example risk assessment for food preparation. Cooking and Service: United Kingdom 2008; P: 2.

6. High Risk Work. [Internet]. 2005 Jun [cited 2011 DEC]. Available from: http://www.safework.sa.gov.au accessed in 12/2011.

7. Florida department of health. Restaurant food security. United State of America, 2001.

8. Health and safety executive (HSE). Health and safety information sheet. United Kingdom, 2004; P: 1.

9. Connecticut department of public health. Working safety in restaurants. United State of America: Hartford 2007; P:2.

10. Work place health and safety. Café and restaurant industry. Queensland, Australia: electrical safety; 2010 .

11. Health and safety authority. Safety, health\& welfare in hotels restaurants. Ireland: catering\& bars 2007; P: 40.

12. Bryan FL. Hazard analysis critical control point (HACCP) system for retail food and restaurant operation. J Food Prot 1990; 53(11):978-83.

13. Jones TF, Pavlin BI, LaFleur BJ, Ingram LA, Schaffner W. Restaurant inspection scores and foodborne disease. Emerg Infect Dis 2004; 10(4):688-92.

14. Al-Hindi A, Jaber B. Cockroaches as mechanical carriers for protozoal and helminthes paeasites in Gaza Strip. Palestine: Un-published work; 2012. 
15. Mourad BA. Food hygiene and safety among cake bakeries in Gaza governorate. [MSc Thesis]. Palestine: Al-Quds University; 2009.

16. Al-Bekr F. Difficulties Facing Freshmen at the University Level at King Saudi University. Educational Sciences: The Journal of King Saud University 2002; 14(37):376.

17. Alam R, Alam JB, Hasan MM, Das SR,
Rahman K, Banik BK. Study of water quality of Sylhet city and its restaurants: health associated risk assessment. J Environ Health Sci Eng 2006; 3(1): 9-18.

18. Onyeneho S N, Hedberg CW. An Assessment of Food Safety Needs of Restaurants in Owerri, Imo State, Nigeria. Int J Environ Res Public Health 2013; 10(8):3296-3309. 